\title{
KESIAPAN PETUGAS PUSKESMAS RENDANG DALAM MENGIMPLEMENTASIKAN PROGRAM JAMINAN KESEHATAN NASIONAL(JKN) KABUPATEN KARANGASEM BALI 2014
}

\author{
I Gusti Agung Gede Darma Putra Suryapranata ${ }^{1}$, I Nyoman Sutarsa ${ }^{2}$ \\ Program Studi Pendidikan Dokter Fakultas Kedokteran Universitas Udayana ${ }^{1}$ \\ Staff Pengajar bagian IKKIKP Fakultas Kedokteran Universitas Udayana ${ }^{2}$ \\ gungjodxt@gmail.com
}

\begin{abstract}
ABSTRAK
Usaha dalam program jaminan kesehatan bagi masyarakat sesungguhnya telah dirintis pemerintah dengan menyelenggarakan beberapa bentuk jaminan sosial di bidang kesehatan. Tahun 2004, dikeluarkan UndangUndang No.40 tentang Sistem Jaminan Sosial Nasional (SJSN) yang mengatur tentang pelaksanaan Jaminan Kesehatan Nasional (JKN) melalui suatu Badan Penyelenggara Jaminan Sosial (BPJS). Tujuan penelitian ini adalah Untuk mengetahui kesiapan petugas Puskesmas Rendang Karangasem untuk mengimplementasikan program JKN. Penelitian ini menggunakan metode penelitian deskriptif kualitatif dengan menggunakan pendekatanfenomenologi. Jumlah sampel yang digunakan sebesar 5 orang, dengan kriteria keakuratan dan validitas informasi yang diperoleh. Penelitian ini dilaksanakan mulai bulan Februari hingga bulan Maret 2014. Hasil didapatkan dinilai dari segi kualitas dan kuantitas, menurut persepektif Petugas Puskesmas faktor SDM dipandang sudah mencukupi. SDM merupakan pilar penyangga utama sekaligus penggerak roda organisasi. SDM yang baik, nantinya dapat menjadi pilar yang kuat dalam melaksanakan program JKN. Gedung dan mobil ambulans sebagai prasarana penunjang pelaksanaan program puskesmas dan JKN, dinilai sudah cukup memadai dari perspektif petugas Puskesmas Rendang.
\end{abstract}

Kata kunci: JKN, Infrastruktur, Sumber Daya Manusia, Puskesmas

\section{INFRASTRUCTURE AND HUMAN RESOURCES AS MOTIVATION FACTOR IN JUDGING READINESS PUSKESMAS RENDANG IMPLEMENT NATIONAL HEALTH INSURANCE FOR TWO MONTHS IMPLEMENTATION}

\section{ABSTRACT}

Efforts to health insurance program for the community actually were pioneered by the government by some forms of social security in the health sector. In 2004, Issued the act no.40 about national social security system that regulates about the implementation of national health insurance (NHI) through a social insurance agent. The purpose of this research is to find readiness of primary health care officers rendang karangasem to implement it. Phenomenology design is used in descriptive qualitative research. Number of samples were 5 people, With the criteria of accuracy and validity of information obtained. This research were done for about 2 months, started from Februari until March 2014. Based on the result obtained discerned from the aspect of quality and quantity, from the perspective of puskesmas officers factors is considered sufficient human resources and infrastructure. Human resources is main pillars supporting areas and locomotion the organization. Good human resources, will become a strong pillars in implementing it. The building and an ambulance as infrastructure supporting the program implementation puskesmas and of these, is considered to be is quite sufficient from the perspective of puskesmas officers rendang.

Keywords : National Health Insurance, Infrastructure, Human Resource, Primary Health Care.

\section{PENDAHULUAN}

Falsafah dan dasar negara Pancasila terutama sila kelima mengakui hak asasi warga atas kesehatan. Jaminan kesehatan bagi penduduk Indonesia sebenarnya telah diatur di dalam UUD 1945 pasal 28H dan pasal 34, dan juga diatur dalam UU No. 23/1992 yang kemudian diganti dengan UU 36/2009 tentang Kesehatan. Dalam UU 36/2009 ditegaskan bahwa 
setiap orang mempunyai hak yang sama dalam memperoleh akses atas sumber daya di bidang kesehatan dan memperoleh pelayanan kesehatan yang aman, bermutu, dan terjangkau. ${ }^{1}$

Usaha dalam program jaminan kesehatan nasional bagi masyarakat sesungguhnya telah mulai dirintis pemerintah dengan membentuk jaminan sosial di bidang kesehatan, diantaranya adalah melalui PT Askes (Persero) dan PT Jamsostek (Persero). Untuk masyarakat miskin dan tidak mampu pemerintah memberikan jaminan melalui skema Jaminan Kesehatan Masyarakat (Jamkesmas) dan Jaminan Kesehatan Daerah (Jamkesda). Namun, skema-skema tersebut masih terfragmentasi sehingga biaya kesehatan dan mutu pelayanan menjadi sulit terkendali. $^{2}$

Indonesia memiliki jumlah penduduk kurang lebih 240 juta jiwa, namun hanya 112 juta jiwa $(46,6 \%)$ yang memiliki asuransi kesehatan sehingg masih ada 128 juta $(53,33 \%)$ penduduk Indonesia yang belum memiliki asuransi kesehatan (Kemenkes RI, 2012). Untuk mengatasi hal tersebut, pada tahun 2004, dikeluarkan Undang-Undang No.40 tentang Sistem Jaminan Sosial Nasional (SJSN) yang mengatur tentang pelaksanaan Jaminan Kesehatan Nasional (JKN) melalui suatu Badan Penyelenggara Jaminan Sosial (BPJS) ${ }^{2}$. Jaminan Kesehatan Nasional (JKN) merupakan bagian dari SJSN yang diselenggarakan dengan menggunakan mekanisme asuransi kesehatan sosial yang bersifat wajib dengan tujuan untuk memenuhi kebutuhan dasar kesehatan masyarakat yang layak untuk diberikan kepada setiap orang yang telah membayar iuran atau iurannya dibayar oleh Pemerintah bagi masyarakat yang tidak mampu ${ }^{5,8}$.

JKN diadaptasi dari negara-negara seperti Jerman, Belanda, Jepang, Korea, Thailand dan Filipina yang menjadikan asuransi kesehatan sosial sebagai pilar utama. Jaminan sosial yang diterapkan negaranegara tersebut mampu mendorong pencapaian cakupan universal (universal coverage) di negaranegara tesebut.Cakupan universal merupakan sistem kesehatan di mana setiap warga di dalam populasi memiliki akses yang adil terhadap pelayanan kesehatan promotif, preventif, kuratif, dan rehabilitatif, yang bermutu dan dibutuhkan, dengan biaya yang terjangkau ${ }^{10,11}$.

Regulasi sistem kesehatan dan program Jaminan Kesehatan Nasional (JKN) nantinya akan memberikan tanggung jawab besar dan strategis kepada pelayanan kesehatan primer khususnya Puskesmas dengan menjadikannya sebagai "gate keeper" dari penyelenggara \& penyampaian pelayanan dasar kesehatan yaitu, Puskesmas menjadi kontak pertama pasien dalam pelayanan kesehatan formal sekaligus penapis rujukan sesuai standar pelayanan medik ${ }^{2}$

Dengan tanggung jawab yang demikian besar tersebut, maka Puskesmas sebagai fasilitas kesehatan primer di masing-masing daerah di Indonesia diharapkan siap untuk mampu menggunakan sumber daya yang telah diberikan oleh pemerintah sebaikbaiknya dengan tidak mengesampingkan aspek pelayanan kesehatan kepada masyarakat. Untuk implementasi hal tersebut, maka diperlukan kesiapan dari infrastruktur puskesmas serta segala pihak khususnya pihak-pihak yang bertugas di Puskesmas agar nantinya dapat terwujud JKN yang efektif dan efisien.

Penelitian ini bertujuan untuk mengetahui kesiapan Puskesmas dalam mengimplementasikan sistem JKN. Salah satu indikator yang dapat dipakai untuk menilai bagaimana kesiapan dari Puskesmas dalam mengimplementasikan JKN adalah dengan mengetahui bagaimana persepsi petugas Puskesmas terkait faktor-faktor pendorong berupa sumber daya manusia dan infrastruktur.

Diharapkan dengan mengetahui faktor penghambat, faktor pendorong dan strategi pelaksanaan JKN dari persepsi petugas Puskesmas Rendang nantinya akan mampu memberikan gambaran secara kasar bagaimana kesiapan petugas dalam melaksanakan sistem JKN sehingga dapat menjadi acuan dalam mengevaluasi pelaksanaan sistem JKN di tingkat puskesmas.

\section{METODE PENELITIAN}

Penelitian ini merupakan penelitian deskriptif kualitatif dengan strategi pendekatan fenomenologi. Penelitian dilakukan di Puskesmas Rendang dari 6 Februari 2014 - 4 Maret 2014 dengan jumlah sampel sebanyak 5 orang. Populasi penelitian ini adalah petugas Puskesmas Rendang yang memiliki keakuratan dan validitas infomasi data serta orang yang benar-benar menguasi masalah diteliti yang memenuhi kriteria inklusi ${ }^{6,9}$.

Penelitian ini dilakukan untuk meneliti bagaimana kesiapan Puskesmas Rendang dalam mengimplementasikan program JKN dilihat dari persepsi dan tingkat pengetahuan petugas puskesmas terkait JKN. Pengambilan sampel dilakukan secara non random sampling purposive. Data yang dikumpulkan berupa data primer. Teknik pengumpulan data yang 
digunakan dalam penelitian ini adalah wawancara secara mendalam (indepth interview). Informan yang dipilih adalah informan yang dianggap tahu tentang topik permasalahan yang bersangkutan, yaitu mewawancarai 5 orang petugas Puskesmas Rendang, Karangasem yaitu Kepala Puskesmas, Dokter Umum, Perawat, Kepala Program JKN, dan Kepala Program PHBS.

Pengumpulan data diperoleh melalui wawancara mendalam pada informan yang hasilnya telah dicatat di kertas maupun yang direkam dengan menggunakan alat perekam. Pertanyaan-pertanyaan wawancara merupakan pertanyaan yang bersifat "open ended" dan sebelumnya telah disusun oleh peneliti agar tetap sesuai dengan fokus penelitian.

Langkah dalam pengumpulan data yang dilakukan peneliti dimulai dengan mengurus izin pada tempat penelitian,mencari sampel penelitian, menjelaskan maksud dan tujuanpenelitian serta pelaksanaan wawancara diikuti dengan penandatanganan lembar persetujuan menjadi responden dan melakukan wawancara mendalam dengan responden.

\section{Hasil}

Lokasi penelitian beralamat di Puskesmas Rendang Kecamatan Karangasem.Penelitian ini menggunakan lima orang petugas Puskesmas Rendang sebagai informan karena dianggap menguasai permasalahan yang sedang diteliti. Informasi dari lima informan tersebut dianggap sudah dapat mewakili aspek yang berkaitan dengan masalah dalam penelitian. Informan tersebut antara lain : Kepala Puskesmas, Dokter Umum, Perawat, Penangung Jawab Program JKN, dan Kepala Program PHBS.

Untuk mengklarifikasi permasalahan Puskesmas Rendang terkait pelaksanaan JKN, peneliti melakukan wawancara terhadap tiga staf JKPM di Dinas Kesehatan Kabupaten Karangasem. Wawancara dilakukan di bagian JKPM di Dinas Kesehatan Kabupaten Karangasem. Peneliti mengklarifikasi isuisu yang muncul dari hasil wawancara dengan petugas Puskesmas Rendang seperti masalah pendanaan, infrastruktur, maupun sosialisasi melalui diskusi kecil yang di lakukan oleh peneliti kepada tiga staf JKPM di Dinas Kesehatan Kabupaten Karangasem.

Dari hasil wawancara yan dilakukan pada lima informan, didapatkan beberapa faktor sebagai pendorong implementasi program JKN di tingkat Puskesmas. Faktor-faktor ini antara lain Sumber Daya Manusia (SDM) yang dinilai dari tingkat pengetahuan dan kesiapan kualitas dan kuantitas SDM serta peneliti menilai dari Infrasruktur Puskesmas.

Tabel 1 menunjukkan karakteristik responden yang melakukan proses wawancara mendalam. Dokter Umum diberikan kode R1, Kepala Puskesmas diberikan kode R2, Penanggung Jawab JKN diberikan kode R3, Perawat diberikan kode R4 dan Kepala Program PHBS diberikan kode R5.

SDM dalam implementasi JKN, memegang peranan penting sebagai komponen utama pelaksanaan program JKN. Komponen SDM terdiri dari pemberi pelayan yang terdiri dari dokter, perawat dan bidan serta pelaksana puskesmas seperti tata usaha dan staf puskesmas. Tingkat Pengetahuan menjadi salah satu hal yang diperhatikan peneliti dalam menilai SDM

Dari hasil wawancara dengan informan, didapatkan bahwa SDM puskesmas dalam pelaksanaan puskesmas dikatakan sudah cukup untuk saat ini. SDM di Puskesmas Rendang dinilai sudah cukup secara kuantitas maupun kualitas Hal ini dapat dilihat dari penuturan Dokter umum dan Kepala Puskesmas

Kalo dari SDM-nya sendiri, kami sudah siap. Karena cukup baik dari segi jumlah maupun kompetensi pendidikan. (R1)

Kalo dari segi pelayanan kita cukup, cukup memadai. (R2)

Hal ini juga ditunjang dengan tingkat pengetahuan petugas Puskesmas yang cukup terkait program JKN. Tingkat pengetahuan ini dinilai dari pengetahuan Petugas terkait aspek kepesertaan JKN , premi, mekanisme pembayaran, dan perbedaan JKN dan JKBM. Berikut penuturan beberapa informan yang menunjukan tingkat pengetahuan yang baik terkait kepesertaan dan premi JKN serta perbedaan JKN dan JKBM.

Kepesertaan JKN ini terdiri dari pekerja formal penerima upah terdiri dari PNS, Polri, TNI ABRI dan peserta Jamsostek dan orang miskin, sedangkan pekerja non formal itu seperti profesional pengacara psikolog, pekerja yng menerima upah dari klienya. Itu disebut dengan kepesertaan JKN mandiri.

Kalau cara pembayarannya yang kita ketahui dengan 3 cara, penerima upah, bukan penerima 
upah dan iuran yang dilaksanakan oleh masyarakat umum. (R5)

Pada dasarnya JKN tu kan scopenya ke nasional, jadi semua masyrakat Indonesia boleh mengikuti JKN lewat BPJS. Sedangkan untuk eee JKBM melayani masyarakat Bali yang ber KTP Bali. (R3)

Informan lain menurut peneliti sudah memahami JKN, jika membandingkan pernyataan informan dengan buku pedoman JKN. Hal yang dinilai lainnya adalah pengetahuan informan terkait tindakan yang ditanggung oleh JKN, dapat dilihat dari penuturan Kepala Puskesmas.

Jadi secara pelayanan mulai dari konsultasi, juga ada pelayanan tertentu seperti pelayanan dasar puskesmas gratis. Yang tidak gratis itu kalo udah yang bersifat rujukan, itulah yang tidak ditanggung. (R2)
Infrastruktur puskesmas merupakan suatu hal penting dalam pelaksanaan JKN. Hal yang dimaksud dengan infrastruktur adalah segala macam peralatan kelengkapan atau benda-benda yang digunakan untuk penyelenggaraan kegiatan, dalam hal ini yang dimaksud adalah gedung dan ambulance.

Sebagian besar responden menyatakan bahwa infrastruktur Puskesmas Rendang yaitu gedung sudah menunjang pelaksanaan JKN . Berikut penuturan Dokter Umum, Kepala Puskesmas dan Kepala Program PHBS terkait penyediaan gedung di Puskesmas Rendang.

Pelayanan JKN ini dari segi gedung saya rasa sudah memenuhi sudah cukup memadai. (R1)

Dari gedungnya juga cukup (R2)

Nah kalau masalah gedung, itu sih udah bagus, udah siap. (R4)

Tabel 1. Karakteristik Informan Penelitian

\begin{tabular}{|l|l|l|l|}
\hline No. & Informan & Tugas & Ket. \\
\hline 1. & Dokter Umum & $\begin{array}{l}\text { Kontak pertama pasien dalam pelayanan kesehatan } \\
\text { formal sekaligus penapis rujukan sesuai standar } \\
\text { pelayanan medik }\end{array}$ & R1 \\
\hline 2. & Kepala Puskesmas & $\begin{array}{l}\text { Memimpin, mengawasi, mengkoordinasikan dan } \\
\text { mengendalikan kegiatan puskesmas dalam } \\
\text { pelaksanaan pelayanan kesehatan secara paripurna } \\
\text { kepada masyarakat di wilayah kerja Puskesmas }\end{array}$ & R2 \\
\hline 3. & $\begin{array}{l}\text { Penanggung Jawab } \\
\text { Program JKN }\end{array}$ & $\begin{array}{l}\text { Bertanggung jawab dalam penyelenggaraan sistem } \\
\text { maupun kepesertaan JKN di wilayah kerja Puskesmas } \\
\text { Rendang, Kabupaten Karangasem. }\end{array}$ & R3 \\
\hline 4. & Perawat & $\begin{array}{l}\text { Petugas kesehatan yang berperan penting dalam } \\
\text { membantu Dokter untuk memberikan pelayanan } \\
\text { kepada masyarakat di era JKN }\end{array}$ & R4 \\
\hline 5. & Kepala Program PHBS & $\begin{array}{l}\text { Bertanggung jawab terhadap pelaksanaan kegiatan } \\
\text { promotif dan preventif di Puskesmas Rendang }\end{array}$ & R5 \\
\hline
\end{tabular}

Puskesmas adalah ujung tombak sistem kesehatan di Indonesia, dimana Puskesmas menjadi kontak pertama pasien dalam pelayanan kesehatan formal sekaligus penapis rujukan sesuai dengan standar pelayanan medik ${ }^{2}$.

Puskesmas diharapkan untuk mengutamakan kegiatan promotif dan preventif kepada masyarakat. Menurut seluruh responden, strategi promotif dan 
preventif yang dilakukan di Puskesmas masih menggunakan pola lama, yaitu melalui program puskesmas keliling dan posyandu. Hal ini masih berlangsung karena belum ada arahan dari BPJS terkait promosi kesehatan kepada masyarakat, dan pola ini masih dirasa efektif oleh Petugas Puskesmas.

BPJS sebaiknya menurunkan arahan terkait sistem promotif dan preventif kepada Puskesmas sehingga pelaksanaan promosi dan preventif ini menjadi dan efektif dibandingkan dengan pola sebelumnya. Hal ini sangat penting karena pada era JKN berpotensi untuk menimbulkan morale hazard. Morale hazard merupakan perilaku seseorang saat resiko akibat tindakannya ditanggung oleh pihak lain ${ }^{7}$ dan hal ini berpotensi menimbulkan kerugian terkait penggunaan sistem kapitasi. Ini pula berhubungan langsung tentang bagaimana petugas memiliki pengetahuan yang cukup mengenai JKN sehingga mampu menyalurkan wawasan kepada warga disekitar mengenai kebaikan dari sistem ini.

Dari hasil wawancara yang telah dilakukan terhadap lima orang informan di Puskesmas Rendang, terdapat beberapa faktor pendorong pelaksanaan JKN di Puskesmas Rendang. Faktor-faktor pendorong tesebut antaraain SDM dan infrastruktur gedung Puskesmas. Dinilai dari segi kualitas dan kuantitas, menurut persepektif Petugas Puskesmas faktor SDM dipandang sudah mencukupi. SDM merupakan pilar penyangga utama sekaligus penggerak roda organisasi. SDM yang baik, nantinya dapat menjadi pilar yang kuat dalam melaksanakan program JKN. Gedung dan mobil ambulans sebagai prasarana penunjang pelaksanaan program puskesmas dan JKN, dinilai sudah cukup memadai dari perspektif petugas Puskesmas Rendang. Dari hal tersebut dapat disimpulkan Puskesmas Rendang telah memiliki modal

\section{DAFTAR PUSTAKA}

1. Departemen Kesehatan RI. 2000. JPKM : Pembinaan, Pengembangan danPendorongan JPKM. DepkesRI, Jakarta.

2. Kemenkes RI. 2014. Buku Pegangan Sosialisasi Jaminan Kesehatan Nasional (JKN) dalam Sistem Jaminan Sosial Nasional.http://www.depkes.go.id/pdf.php?pg =JKN-SOSIALISASI-ISI FA REV. Diakses tanggal : 8 Februari 2014

3. Kemenkes RI. 2013. Kumpulan Peraturan Jaminan Kesehatan. internal yang kuat yaitu SDM dan ditunjang dengan ketersediaan gedung sebagai wadah pelaksanaan pelayanan kesehatan kepada masyarakat yang berkesinambungan.

\section{PENUTUP}

\section{Simpulan}

Dari penelitian yang sudah dilakukan selama satu bulan terhadap petugas Puskesmas Rendang, peneliti dapat menyimpulkan :

1. Faktor pendorong yang menonjol dalam pelaksanaan JKN di Puskesmas Rendang adalah SDM sebagai roda penggerak program dalam hal ini tenaga medis yang sudah cukup dari segi kualitas dan kuantitas

2. Gedung representatif sebagai penunjang utama berjalannya suatu program pelayanan di Puskesmas Rendang.

\section{Saran}

Agar dilakukan penelitian kualitatif lebih lanjut untuk meneliti kesiapan Puskesmas Rendang dalam mengimplementasikan JKN.Puskesmas Rendang diharapkan melakukan terobosan dalam rangka pengembangan kegiatan promotif dan preventif yang menjadi faktor utama keberhasilan Puskesmas dalam era sistem kapitasi ini tentu bergantung dari sumber daya manusia atau petugas puskesmas itu sendiri kemudian BPJS selaku penyelenggara JKN agar dapat melihat berbagai masalah yang telah muncul dalam beberapa bulan implementasi ini dan segera mencari solusi sehingga Puskesmas sendiri memiliki arahan jelas sebagai ujung tombak pelayanan kesehatan di Indonesia dalam upaya meningkatkan kualitas hidup penduduk.

https://app.box.com/s/34609nrhbtesa28dc3n2 . Diakses : 8 Februari 2014

4. Kemenkes RI . 2012. Penerapan Asuransi Kesehatan Sosial di Indonesia, sesuai kah ?. http://www.kpmak-ugm.org/2012-05-12-0454-35/2012-05-12-050345/article/650penerapan-asuransikesehatan-sosial-diindonesia,-sesuai-kah. Diakses tanggal : 14 Februari 2014

5. Menkokesra. 2014. Puskesmas Sebagai Ujung Tombak JKN Harus Direvitalisasi. http://www.menkokesra.go.id/content/puskes mas-sebagai- ujung-tombak-jkn-harusdirevitalisasi. Diakses tanggal : 8 Februari 2014 
6. Miles, M.B. dan Huberman, A.M. 1984.

Qualitative Data Analysis: A Sourcebook of NewMethods. Beverly Hills CA: Sage Publications, New York.

7. Pengurus Besar Ikatan Dokter Indonesia (PBIDI). 2013. Metode Membayar Dokter Layanan Primer Dalam Era Jkn. www.idionline.com/Metode-Membayar-DLPdi-Era-Jkn-7-okt-2013. Diakses tanggal : 8 Februari 2014

8. Pusat Promosi Kesehatan (Promkes) Depkes RI. 2014. Mengapa Perlu Jaminan Kesehatan Nasional.

http://www.promkes.depkes.go.id/index.php/t
opik/115-jaminan-kesehatan-nasional.Diakses tanggal : 8 Februari 2014.

9. Sutopo H.B. 2002. Metodologi Penelitian Kualitatif. Sebelas MaretUniversity Press, Surakarta.

10. WHO. 2005. Achieving universal health coverage: Developing the health financing system. Technical brief for policy-makers. Number 1, 2005. World Health Organization, Department of Health Systems Financing, Health Financing Policy, United States.

11. Limwattananon S, dkk. 2012. Why has the Universal Coverage Scheme in Thailand achieved a pro-poor public subsidy for health care?. BMC Public Health. 12(1) : 1 -11 